philosophers, especially Kyburg and Hacking who have written on probabilistic ideas and is critical of Popper's appreciation of scientific knowledge. And yet his treatment is often realistic, since it is always set against this decision-making, operational background. Thus he criticizes the adherents of the likelihood view, and Shackle in particular, by saying:

The point is, that calling a mode of appraisal a way of measuring or assessing support is not helpful. A specification of the use or function of the mode of appraisal in inquiry and deliberation is needed, whether the method is probabilistic or not.

This is not an easy book to read. It is very long and parts of it are rather technical. For someone concerned with logical questions, his definitions are not as crisp or as clearly laid out as one might wish. There are many parts where the language is turgid; this is his definition of L-irrelevant:

the information that a trial is of kind $T$ is $L$-irrelevant to the issue as to whether an $\mathrm{R}$ occurs on that trial relative to information that the trial is of kind $S$ if and only if $\mathrm{K}$ contains the information that being of kind $T$ is stochastically irrelevant to yielding an $\mathrm{R}$ on a trial of kind $\mathrm{S}$.

A more serious point of style that disturbs me is his failure to help the book's readability by adopting standard notation. For example, experts in the probability calculus use $p(A / B)$ for the probability of A given $B$. Whey then use $Q(h ; e)$ ? And why use irrelevant instead of independent? Much of the later sections of the book are difficult going because of the apparently unnecessary changes of language and notation.

It is a pity that Levi has so little to say about works of the "strict" Bayesians, de Finetti, Jeffreys, Savage, Ramsey and others. Is he fully aware of the basic result that a man who is to act sensibly can only do so if he acts in accordance with a unique probability and a unique utility? And why is there no mention of exchangeability, that brilliant notion expounded by de Finetti in his two-volume treatise Theory of Probability (Wiley, 1974/5), that connects chance with belief and embraces the frequentist framework within that of knowledge? Levi says in his discussion of nuclear safety, that "the available evidence fails to warrant a sufficiently definite system of credal probability judgments"; but probability is the only description of the available evidence, as Ramsey and others have shown. We may not like the evidence, but probability should not be the scapegoat.

Where does this book stand as a contribution to the study of knowledge? Its importance lies in its new emphasis on a general, credal probability and in its forward-looking, decision-orientated view of knowledge. It leads us further along the road towards a philosophically satisfying, yet usable, appreciation of scientific method: an appreciation that could do much in a really practical way to assist the development of science and technology. And yet, is that not already with us in the work of the "strict" Bayesians? It is to be hoped that scientists will think about these issues, and read de Finetti and Jeffreys as well as Levi.

D.V.Lindley was formerly Professor of Statistics and Head of the Department of Statistics and Computer Science at University College London.

\title{
Fit for mankind: a vision of Earth
}

\section{Paul A. Colinvaux}

The Wooing of Earth. By René Dubos. Pp.183. (Athlone/Scribner's: 1980.) £7.50, \$8.95.

To woo the Earth means to coax our countrysides into the human image of what the good Earth should be. And the image is often very good; a land fair and open, contrived to reflect an ancient savanna where our speices was moulded by evolution, long, long ago. We have done this everywhere and the carpers among us are wrong to call our doings bad. This is the Dubos message of good cheer.

Europe is beautiful, with its vistas of villages, pastures and trees. The European wilderness of the old times, where immense, dark forest forever hid the view, was a frightening place. Greece is delightful, even though its shimmering hillsides are only kept bare by relentless overgrazing. New Englanders like their patterns of village and farm, and their legislators are trying to stop land going back to forest as farms are abandoned. Lovely parklands like the Han dynasty Summer Palace or the creations of Capability Brown are not wilderness but nature contrived to fit the human appetite. Hardly any of us want wilderness. Why not admit this - and be optimistic about how we can change the Earth without ruining it.

Dubos points out that the sainted Thoreau had a comfortable time at Walden Pond, close to the safety of tranquil Concord, and that the sight of a real wilderness of trees in Maine shocked him to hasty retreat. We pay lip service to the wilderness, but most still turn away from its frightening possibilities. We urge Africans to save the game herds, but the Africans will destroy them before the year 2000 because farm land is better than wilderness supporting wild beasts. This seems so self-evident that I have long marvelled at the hopes of those who thought the Serengeti would be saved. We

\section{New books from IRL}

\section{Nucleic Acids \\ Synthesis:}

Applications to Molecular Biology and Genetic Engineering

Proceedings of the International Symposium on Chemical Synthesis of Nucleic Acids. Held May 1980 in Egestorf, West Germany.

Nucleic Acids Symposium Series No. 7.

In the fields of molecular biology and genetic engineering, synthetic nucleic acids and their constituents have proved to be valuable tools and their uses appear to be infinite. in the present era of 'synthetic biology' it is not surprising that the chemical synthesis of nucleic acids is experiencing a tremendous renaissance. Thus, it was most opportune that this conference, organized by Hubert Köster, should have been held, and the list of participants reads like a 'Who's Who' in the field, together with representatives from industry. This issue of the Nucleic Acids Symposium Series contains details of the latest methods in oligonucleotide synthesis from practicaliy all the leading laboratories in the world including those laboratories in pre wold, including those or Eastern Europe, Japan and China and serves as a source not only of their curren (and usually unpublished) research, but also of their predictions for the future of the methodology and the use of such oligonucleotides.

396 pp ISBN 0904147266 (Hard) August 1980 £17.00/US\$40.00

Obesity: A Bibliography 1974-1979

340 pp ISBN 0904147177 (Hard) 乏22.50NS $\$ 55.00$

October 1980

\section{Olfaction and Taste VII}

Proceedings of the Seventh Internationa Symposium on Olfaction and Taste and Fourth Congress of the European Chemoreception Research Organisation. Held July 1980 in the Netherlands. 500 pp ISBN 0904147207 (Hard) $£ 22.00$ NS $\$ 50.00$

November 1980

\section{Immunology of the Eye} Workshop 1:

Immunogenetics and Transplantation Immunity

Proceedings of a Workshop on Immunogenetics and Transplantation Immunity. Heid December 1979 in

Chantilly, Virginia.

Edited by George M. Steinberg, Igal Gery and Robert $B$. Nussenblatt

286 pp ISBN 0904147258 (Soft) $£ 10.00$ NS $\$ 25.00$

November 1980

Forthcoming Proceedings in the Immunology of the Eye Workshop Series

Autoimmune Phenomena Infection, Inflammation and Allergy

\section{IRL Information Retrieval}

1 Abbey St., Eynsham

Oxford OX8 $1 \mathrm{~J}$, England

Suite 815, Fisk Building.

250 West 57 th Street. New York NY 10019, U.S.A. 
destroyed our wild animals in Europe and North America, and took their land; we even make newspaper headlines of the escape of a lion from the zoo and public peace comes back only when it is known that the animal is shot. Why should we expect poor farmers of Africa to act differently?

Dubos stresses that they will not, that people do not like wilderness, that we may save some areas as places for adventuring or because it seems sense to keep the gene pools of wilderness species as intact as possible, but that we ought to replace most wilderness with something even better.

Dubos is asserting that there is a silent majority of people who want a friendly, humanized Earth to live on - not danger, not wilderness, not even what is productive or the result of good ecological management, but what is familiar or beautiful. Doubtless he is right, and doubtless the silent majority will have its way. I worry, though, at the tyranny of majorities to those few who, people-like, do not always run with the herd. A real wilderness is marvellous in ways that Thoreau could never feel. A desolate mountain top in the Brooks Range is a better place to be than a man-made space above the English Lakes. To stand, thinking yourself into invisibility in the Amazonian forest, alone and as the hours pass, cannot be equalled in a botanic garden or in the landscapes of a potentate. A proper wooing of Earth will see that she keeps bits of her wild temper intact.

Dubos tries to show that what people like is what they were programmed to like in ancient days when our species was fashioned in some forgotten African savanna. These parts of the book make uncomfortable reading. We are the learning species, the animal who learned to live in almost every habitat of the Earth before we discovered, through agriculture, how to transform our habitats. Yet Dubos sees the Peking Summer Palace as an attempt to recreate the supposed savanna of our species' youth. This has a feel of genetic determinism about it which is not quite nice. The essential thesis of wooing the Earth can stand without this.

Nor does the Dubos thesis need bolstering by ecological theory, yet his is a conservation ethic of sorts and all conservation nowadays argues before the "Court of Ecology". Dubos would have done better not to, for his is still the ecology of the environmental movement with the standard errors.

It is not a fact that ecosystem complexity yields stability. This was a hypothesis of the 1960 s, built out of inspired speculating by Robert MacArthur (Ecology 36, 533-536; 1955) who drew mathematical analogies between junctions in information networks and species in ecosystems. By the mid-1970s, R.M. May (Stability and Complexity in Model Ecosystems; Princeton University Press, 1974), D. Goodman (Q. Rev. Biol. 50, 237-266; 1975) and others had shown how unrealistic this was and many of us ecologists felt grave disquiet years before then. Modern conservationists appealing to ecological Courts really must read up the latest Court Decisions before applying their ecological law.

It is dangerous practice to talk about how ecosystems "evolve"; change they do, but to talk of them "evolving"' suggests a mechanism of selection, of the stable replacing the unstable, the productive the unproductive. There are indeed ecologists who seek supra-organismal patterns of evolution like these - but they are not all of the profession and they may not be the wave of the future. Far better to remember that most of the energy flux used to drive an ecosystem is degraded in the non-living portions. In temperate forest some 0.7 per cent of incident solar energy enters the biota through photosynthesis and the other 99.3 per cent is degraded by raising temperatures or evaporating water $(\mathrm{H}$. Lieth and R. H. Whittaker. Primary Productivity of the Biosphere; SpringerVerlag, 1975).

The biota adapt to this energetic reality much more than they control it. Progress towards a nebulous "climax" is a shuffling in line before the energy soup-kitchen, until everyone has found a place of sorts and there is a quasi peace. Incidentally, this is why our human systems have, in general, worked so well; we have altered the arrangement in the biological energy queue without tampering with the main patterns of energy flux. It is only when we do something terrible to the landscape, such as promoting soil erosion or building a dam, that major diversions in primary energy flux reflect true system instability.

Dubos has a wise and sane vision - an Earth kept diverse and pleasant for human use, made richer by human invention than wild nature had left it. Leave some wilderness for some of us to spend a few hours in and change the rest, ever so gently, until it is good. Yet he protests how well he understands that all will be vain if our numbers keep on growing and that much will be imperilled if we go to nuclear war. But on the ecological subject of human numbers he has nothing to say. He believes that the remorseless rise of population has something to do with curbs in the death rate made by the medical profession and he savours the hope that our numbers may be levelling off. These are views not tenable in ecological logic. Numbers rise because the human breeding strategy remains that of achieving optimum clutch and the destructions Dubos fears will come about as we seek to find adequate niche-space for the surplus individuals that result (P.A. Colinvaux Nature 26, 256-357; 1976. The Fates of Nations; Simon and Schuster).

Yet it is good to read honest statements that all things done by mankind to the environment are not bad; indeed that most things done have had satisfactory results.

Paul Colinvaux is a Professor in the Department of Zoology at The Ohio State University.

\section{Survival of the fittest author}

\section{Wilma George}

A Delicate Arrangement: The Strange Case of Charles Darwin and Alfred Russel Wallace. By Arnold C. Brackman. Pp. 370. (Times Books: 1980.) \$12.50.

THIS is a disappointing book. It promises to uncover a plot but fails to convince and fills up pages with incomplete biography. Many people would agree with the author that Alfred Russel Wallace had less than his fair share of publicity but few would agree with his interpretation that Darwin cheated Wallace and that Lyell and Hooker connived at the plot.

Brackman rests his case on dates: the supposed date that Wallace sent his natural selection paper to Darwin and the supposed date that Darwin received it. Wallace thought he sent it in March 1858 and Darwin thought he received it on 18 June but Wallace's envelope with its postmark has not survived. Brackman claims that because Wallace posted a letter to F. Bates on 9 March which arrived on 3 June he must have posted his article to Darwin on the same date and, therefore, the article must have arrived on 3 June.
This is not evidence. This same "evidence" has been used by H. Lewis McKinney in Wallace and Natural Selection (Yale University Press, 1972) to claim that Wallace cheated (to say he was where he was not).

Brackman claims that Darwin cheated by saying he had received Wallace's article on 18 June (and not 3 June) in order to quarry it for data and ideas before writing to Lyell. The "evidence" is supported by the fact that Darwin did not keep letters during the $1850 \mathrm{~s}$ - and that Wallace was a member of the lower classes.

Brackman implies that Charles Darwin or his son Francis destroyed letters because Wallace was writing to Darwin about his ideas on species. But Darwin did not keep letters systematically until he became famous. Brackman also implies that Darwin was surreptitiously using Wallace's 1855 paper on species when the 1855 paper was in print!

Brackman's narrative style is "surreptitious", to say the least: "A troubled Darwin opened Wallace's letter". In fact, it is downright dishonest: "For Darwin his success in securing Wallace a 